\title{
IMIA Yearbook Special Topics
}

1992: Advances in an Interdisciplinary Science

1993: Sharing Knowledge and Information

1994: Advanced Communications in Health Care

1995: The Computer-based Patient Record

1996: Integration of Information for Patient Care

1997: Computing and Collaborative Care

1998: Health Informatics and the Internet

1999: The Promise of Medical Informatics

2000: Patient-centered Systems

2001: Digital Libraries and Medicine

2002: Medical Imaging Informatics

2003: Quality of Health Care: The Role of Informatics

2004: Towards Clinical Bioinformatics

2005: Ubiquitous Health Care Systems

2006: Assessing Information Technologies for Health

2007: Biomedical Informatics for Sustainable Health Systems

2008: Access to Health Information

2009: Closing the Loops in Biomedical Informatics

2010: Biomedical Informatics: Building Capacity Worldwide

2011: Towards Health Informatics 3.0

2012: Personal Health Informatics

2013: Evidence-based Health Informatics

2014: Big Data - Smart Health Strategies

2015: Patient-Centered Care Coordination

2016: Unintended Consequences: New Problems and New Solutions 